\begin{tabular}{c|c|c}
\hline \hline & MARINE ECOLOGY PROGRESS SERIES \\
Vol. 266: 265-272, 2004 & Mar Ecol Prog Ser & Published January 30 \\
\hline
\end{tabular}

\title{
Accuracy of geolocation estimates for flying seabirds
}

\author{
R. A. Phillips*, J. R. D. Silk, J. P. Croxall, V. Afanasyev, D. R. Briggs \\ British Antarctic Survey, Natural Environment Research Council, High Cross, Madingley Road, Cambridge CB3 0ET, UK
}

\begin{abstract}
Geolocation (Global Location Sensing or GLS logging) using archival light-recording tags offers considerable potential for tracking animal movements, yet few studies of flying seabirds have exploited this technology. Our study evaluated its effectiveness for determining foraging ranges of black-browed albatrosses Thalassarche melanophrys fitted simultaneously with GLS loggers and satellite-transmitters (Platform Terminal Transmitters, PTTs). After some preliminary validation, the position of an albatross could be determined by geolocation with a mean error \pm SD of $186 \pm 114 \mathrm{~km}$ (SDs of $1.66^{\circ}$ and $1.82^{\circ}$ of latitude and longitude, respectively). Errors from identical static loggers were lower (mean \pm SD of $85 \pm 47 \mathrm{~km}$, with overall SDs of $0.61^{\circ}$ and $0.99^{\circ}$ of latitude and longitude, respectively) and less variable, with the difference attributable to variation in sensor orientation, intermittent shading by plumage, and the difficulty of correcting for extensive, potentially non-linear movements of flying birds. Iterative smoothing reduced both the mean error and the inflation of kernel ranges derived from GLS data, but over-smoothing contracted the extremes of the range. This reduced the overlap with radial cores apparent in the control data, and should be avoided for multinuclear GLS fix distributions. The accuracy of GLS tags is more than adequate for tracking migration and breeding-season foraging ranges of pelagic species, and for identifying broad-scale habitat preferences, overlap and potential conflict with commercial fisheries.
\end{abstract}

KEY WORDS: Geolocation · Error estimation · Kernel analysis · Smoothing $\cdot$ Albatrosses

\section{INTRODUCTION}

Recent refinements in solid-state electronics and the development of lightweight transmitters and loggers have transformed the investigation of temporal and spatial variation in habitat use of marine animals, and the relationships between at-sea distribution and environmental characteristics (Prince et al. 1998, Le Boeuf et al. 2000, Block et al. 2001, Wilson et al. 2002). Much of this information has been collected using satellite tags (Platform Terminal Transmitters, PTTs). These send a brief radio signal to polar-orbiting NOAA satellites, with the location calculated from the Doppler shift in transmission frequency as the satellite moves relative to the PTT. Although this technology has proved very effective for a diverse range of marine and terrestrial taxa, there are inherent limitations. One is the considerable expense involved in purchasing devices and processed satellite data. Another is instrument size and shape, with even the smallest of the current generation presenting potential problems in terms of hydrodynamic drag for small penguins and increased wing-loading for flying seabirds (Wilson et al. 1986, Culik et al. 1994, Phillips et al. 2003). Longterm attachment can also prove difficult, particularly for seabirds, as devices taped or glued to feathers are lost during the winter moult, and the use of harnesses is not currently a satisfactory alternative (Phillips et al. 2003). Consequently, much more is known about breeding-season activities, when adults are centralplace foragers constrained to return to land to incubate or feed offspring, than about foraging strategies and ranges during migration.

An alternative to satellite-telemetry for determining habitat use is geolocation (Global Location Sensing or GLS logging). To date, this has been applied to a small 
(but taxonomically diverse) range of species that include tuna, seals, penguins and albatrosses (Delong et al. 1992, Wilson et al. 1995, Tuck et al. 1999, Weimerskirch \& Wilson 2000, Block et al. 2001). GLS loggers record ambient light, from which sunset and sunrise times are estimated from thresholds in light curves; latitude is derived from day length, and longitude from the time of local midday with respect to Greenwich Mean Time and Julian day (DeLong et al. 1992, Wilson et al. 1992, Hill 1994). The advantages over PTTs are reduced costs (with no satellite requirements), small size, extended battery life, and if attached securely (for example, to a leg band on a flying seabird), indefinite device retention. Disadvantages are that recapture is necessary before data can be downloaded, only 2 locations (ca. local midday and midnight) are available per day, and it is impossible to estimate latitude for variable periods around the equinoxes (Wilson et al. 1992, Hill 1994). Accuracy is also much lower and more variable for several reasons (Hill 1994, Wilson et al. in press). Mean errors following filtering (to remove unrealistic fixes) or smoothing (to reduce variability in errors) range from 19 to $140 \mathrm{~km}$ for static devices and $<40$ to $380 \mathrm{~km}$ for free-ranging penguins and seals (see 'Discussion'), with one study concluding that performance was too low even to permit intra-seasonal or inter-specific comparisons in foraging areas (Hull 1999).

Despite its apparent potential to help identify key foraging areas and migration routes, information critical for understanding predator-prey interactions and for targeting conservation efforts, only a few studies of flying seabirds have exploited GLS technology (Tuck et al. 1999, Grémillet et al. 2000, Nel et al. 2000, 2002, Weimerskirch \& Wilson 2000). This reflects partly the relatively recent introduction of miniaturized loggers, but also the paucity of information on accuracy for this type of application. Our study was designed to highlight the utility of the approach, as well as evaluate its effectiveness in delineating the foraging ranges of breeding black-browed albatrosses fitted simultaneously with both GLS loggers and satellite-transmitters. To do so, we compared accuracy of position estimates and overlaps in kernel estimates of home range sizes after data processing by several filtering and smoothing techniques. As far as we are aware, this is the first published study to assess rigorously the performance of GLS loggers on a flying seabird.

\section{MATERIALS AND METHODS}

Fieldwork was carried out at Bird Island, South Georgia $\left(54^{\circ} 00^{\prime} \mathrm{S}, 38^{\circ} 03^{\prime} \mathrm{W}\right)$ on black-browed albatrosses Thalassarche melanophrys. Shortly after the end of brooding (late January 2002), 12 adults were fitted with $30 \mathrm{~g}$ satellite-transmitters (PTT 100; Microwave Telemetry), a $9 \mathrm{~g}$ combined salt-water switch and GLS logger (British Antarctic Survey, for details see Afanasyev in press), and a $17 \mathrm{~g}$ radio-transmitter with an internal loop antenna (Sirtrack). The radiotransmitters allowed exact arrival and departure times to be recorded using an automatic radio-receiver logger system. Each PTT was attached to 6 to 8 mantle feathers using Tesa ${ }^{\circledR}$ tape, and the logger and radiotransmitter attached to $30 \mathrm{~mm}$ high plastic bands fitted to each tarsus. Total instrument mass corresponded to ca. $1.7 \%$ of the mean mass of adults at the end of the brood-guard period. Devices were left on adults for successive foraging trips until retrieval 50 to 60 d later, with the exception of 1 bird whose nest failed $52 \mathrm{~d}$ after deployment, and whose devices were retrieved the next year. PTT deployment had no significant effect on mean foraging trip duration, breeding success, or probability of returning in the following season (Phillips et al. 2003).

The GLS loggers measured intensity of visible light every $60 \mathrm{~s}$, and recorded the maximum reading within each 10 min interval. Light data were analysed using MultiTrace software (Jensen Software Systems) with the correction factor for the relative distance travelled during the day compared with the night set to 0.7 (based on the PTT data). Given the inaccuracy of latitude estimation during equinoxes (Hill 1994), analysis was restricted to the period from device deployment to the point when location estimates were clearly affected (ca. 2 wk prior to the vernal equinox). Any locations derived from light curves with obvious interruptions or interference around the times of sunset or sunrise (probably a result of changes in orientation or intermittent shading of the sensor; see 'Discussion') were noted during processing and subsequently excluded if obviously anomalous (Hill 1994). Data were then processed in 1 of 2 ways: (1) an iterative forward/ backward-averaging filter (McConnell et al. 1992) was run to remove any locations that required unrealistic flight speeds (>35 $\mathrm{km} \mathrm{h}^{-1}$ sustained over a $48 \mathrm{~h}$ period, based on the PTT data); or (2) iterative smoothing was applied, i.e. the interpolation of intermediate fixes between successive locations (Pütz 2002, Wilson et al. in press), with fixed start and end points around any periods of missing data. Data were smoothed 2, 4, 6 or 8 times, and the iterative speed filter then applied to remove the few unlikely locations remaining $(0.7,0.3$, 0.1 and $0 \%$, respectively). The great-circle distance between consecutive fixes was used in all velocity calculations.

A speed filter (McConnell et al. 1992) was also used to validate PTT data (Service ARGOS Location Classes $0-3, \mathrm{~A}$ and $\mathrm{B})$, in this case allowing a maximum permissible velocity of $80 \mathrm{~km} \mathrm{~h}^{-1}$ because of the much 
shorter sampling intervals compared with GLS fixes. To estimate the errors in geolocation, we calculated the deviation in latitude, longitude and great-circle distance for each unsmoothed and smoothed GLS fix from the mean position of all valid PTT locations obtained during the corresponding day or night. In addition, for unsmoothed locations, potential consistency among birds and among days in great-circle, latitudinal and longitudinal errors were examined using ANOVA. For these analyses, midnight fixes only were used: (1) because the mean PTT fix is likely to better represent the actual position, as the albatrosses travelled less at night than during the day (based on PTT data); and (2) to reduce the problem of lack of serial independence of consecutive locations calculated from the same dawn or dusk event. The few nights when a GLS location was available from only 1 bird were excluded. As the distribution of errors in great-circle distance had a slight right skew, analyses were performed on square-root transformed data (which did conform to a normal distribution).

Fixed kernel home range analyses were performed separately for mean PTT, smoothed and unsmoothed GLS datasets, using the Animal Movement extension in Arcview GIS 3.2 (ESRI). The most appropriate smoothing parameter $(h)$ was chosen via least squares cross-validation (Worton 1989) for the unsmoothed GLS data, and then applied as standard for the other datasets. Although locations were not serially independent, this is not a requirement for kernel analysis (De Solla et al. 1999). Density contours corresponding to 95, 90 and $50 \%$ kernels were calculated for locations in a Lambert Equal-Area Azimuthal (South Pole) projection, and overlaps in foraging ranges between GLS and mean PTT kernels calculated. An additional kernel analysis was run incorporating all valid PTT fixes obtained throughout the study period to check if this would be a better representation of the maximum extent of foraging areas. In fact, these kernels were more or less indistinguishable from those estimated using mean PTT fixes, and are not considered further.

In addition, GLS data were available from 3 static devices deployed at Bird Island at a similar time in the previous year (5 December 2000-17 February 2001). These data were processed using MultiTrace, as above, and results compared with device locations determined using differential GPS. Potential consistency in errors (great-circle distances) among devices and among days was examined using ANOVAs, with midday fixes only used in the comparisons to reduce the problem of lack of serial independence.

\section{RESULTS}

\section{Free-ranging albatrosses}

Concurrent GLS and PTT data were obtained for the 12 black-browed albatrosses for a total of 138 complete, and 12 incomplete foraging trips. Filtering because of light-level interference and unrealistic flight speeds removed 12.2 and $2.0 \%$, respectively, of the original GLS locations, with considerable variation among birds (Table 1). The distribution of all unsmoothed GLS, and the corresponding mean PTT locations are shown in Fig. 1. The overall mean distance between the valid GLS and mean PTT locations was $186 \mathrm{~km}$, with overall SDs in latitudinal and longitudinal errors of $\pm 1.66^{\circ}$ and $\pm 1.82^{\circ}$, respectively (Table 1 ). There was consistent variation among birds in greatcircle and latitudinal, but not longitudinal errors $\left(F_{11,329}=3.61, \mathrm{p}<0.001, F_{11,329}=1.92, \mathrm{p}<0.05\right.$ and

Table 1. Thalassarche melanophrys. Summary of position estimates using geolocation for free-ranging black-browed albatrosses

\begin{tabular}{|c|c|c|c|c|c|c|}
\hline Bird ID & $\begin{array}{l}\text { No. of valid } \\
\text { locations }\end{array}$ & $\begin{array}{l}\text { No. of locations with } \\
\text { light-level interference }\end{array}$ & $\begin{array}{l}\text { No. of locations failing } \\
\text { velocity filter }\end{array}$ & $\begin{array}{l}\text { Mean great-circle } \\
\text { error } \pm \mathrm{SD}(\mathrm{km})\end{array}$ & $\begin{array}{l}\text { SD of latitudinal } \\
\text { error }\left({ }^{\circ}\right)\end{array}$ & $\begin{array}{c}\text { SD of longitudinal } \\
\text { error }\left({ }^{\circ}\right)\end{array}$ \\
\hline B182 & 52 & 0 & 1 & $161 \pm 82$ & 1.37 & 1.27 \\
\hline O071 & 49 & 29 & 0 & $201 \pm 105$ & 1.64 & 2.03 \\
\hline O093 & 54 & 5 & 0 & $217 \pm 107$ & 1.55 & 1.96 \\
\hline O094 & 51 & 12 & 2 & $251 \pm 132$ & 2.06 & 2.71 \\
\hline O150 & 35 & 12 & 0 & $176 \pm 86$ & 1.49 & 1.57 \\
\hline O205 & 66 & 0 & 5 & $143 \pm 131$ & 1.49 & 1.45 \\
\hline O293 & 67 & 6 & 1 & $175 \pm 106$ & 1.51 & 1.95 \\
\hline O296 & 56 & 0 & 1 & $198 \pm 139$ & 1.93 & 1.69 \\
\hline O474 & 68 & 0 & 0 & $145 \pm 84$ & 1.29 & 1.24 \\
\hline O626 & 53 & 12 & 0 & $233 \pm 125$ & 1.93 & 2.05 \\
\hline W675 & 90 & 0 & 4 & $174 \pm 106$ & 1.57 & 1.62 \\
\hline W685 & 43 & 21 & 2 & $187 \pm 91$ & 1.51 & 1.93 \\
\hline All & 684 & 97 & 16 & $186 \pm 114$ & 1.66 & 1.82 \\
\hline
\end{tabular}




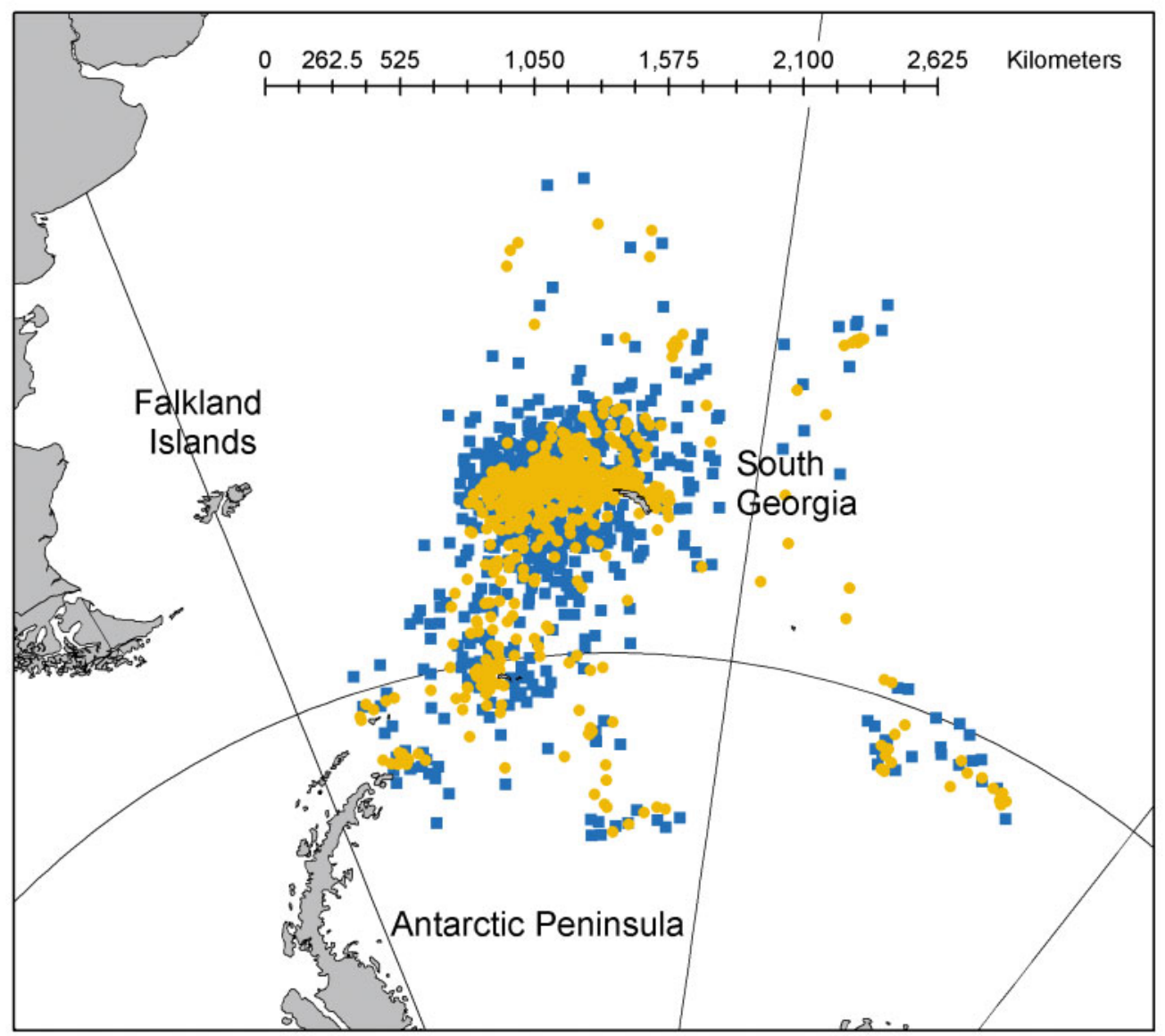

Fig. 1. Thalassarche melanophrys. Distribution of Global Location Sensing (GLS, blue), and corresponding mean Platform Terminal Transmitter (PTT, yellow) locations for 12 freeranging black-browed albatrosses tracked from South Georgia during chickrearing in 2002

$F_{11,329}=1.19$, not significant $[\mathrm{NS}]$, respectively), and also among nights in great-circle, latitudinal and longitudinal errors $\left(F_{42,298}=1.60, \mathrm{p}<0.05, F_{42,298}=1.67, \mathrm{p}<\right.$ 0.01 and $F_{42,298}=1.86, \mathrm{p}<0.005$, respectively).

Errors (great-circle distances) were reduced by $9 \%$ from a mean of $186 \mathrm{~km}$ for the unsmoothed data, to $169 \mathrm{~km}$ after smoothing twice, then by a further $3 \%$ to $164 \mathrm{~km}$ after smoothing 4 times, but with little improvement thereafter (Table 2). There was considerable variation between individuals in the degree to which repeated smoothing influenced errors, with the greatest improvement apparent for birds that tended to travel less far from the colony.

Kernel density contours for valid unsmoothed and smoothed GLS locations, overlaid on kernels from the mean PTT locations are shown in Fig. 2. For each density contour $(50,90 \%$ and $95 \%)$, the GLS kernel based on the original valid locations (unsmoothed) encompassed a high proportion of the corresponding PTT kernel, but not vice versa. Each iteration of the smoothing procedure reduced the inflation of the GLS range, but gradually drew in the extremes of the distribution, resulting in increasing exclusion of parts of the PTT range.

\section{Static data}

No interference to dawn or dusk light curves was evident in data from the static GLS loggers. The overall mean distance from the GLS estimate to the known location of each device was $84.7 \mathrm{~km}$, with overall SDs in latitudinal and longitudinal errors of $0.61^{\circ}$ and $0.99^{\circ}$, respectively (Table 3). Considering midday fixes only, there were no consistent differences between devices in great-circle, latitudinal or longitudinal errors $\left(F_{2,219}=0.02, \mathrm{NS}, F_{2,219}=0.07, \mathrm{NS}\right.$ and $F_{2,219}=0.06, \mathrm{NS}$, respectively). In contrast, there were highly consistent differences between days in great-circle, latitudinal and longitudinal errors $\left(F_{73,148}=62.5, \mathrm{p}<0.001\right.$, $F_{73,148}=156.1, \mathrm{p}<0.001$ and $F_{73,148}=155.8, \mathrm{p}<0.001$, respectively).

\section{DISCUSSION}

The mean error in GLS locations from the static loggers was $85 \mathrm{~km}$, and from those on the 12 free-ranging black-browed albatrosses was $186 \mathrm{~km}$ for unsmoothed data, reduced to $169 \mathrm{~km}$ after smoothing twice. These 
Table 2. Thalassarche melanophrys. Effects of smoothing on great-circle errors from GLS loggers on free-ranging black-browed albatrosses

\begin{tabular}{|c|c|c|c|c|c|c|c|}
\hline \multirow[t]{2}{*}{ Bird ID } & \multirow[t]{2}{*}{$\begin{array}{l}\text { No. of valid } \\
\text { locations }\end{array}$} & \multicolumn{5}{|c|}{$\begin{array}{ll}\text { Unsmoothed } & \text { Mean great-circle error } \pm \mathrm{SD}(\mathrm{km}) \\
\quad \text { Number of times data were smoothed }\end{array}$} & \multirow[t]{2}{*}{$\begin{array}{l}\text { Mean distance } \\
\text { from colony }(\mathrm{km})\end{array}$} \\
\hline & & & $2 \times$ & $4 \times$ & $6 \times$ & $8 \times$ & \\
\hline B182 & 52 & $161 \pm 82$ & $141 \pm 72$ & $132 \pm 66$ & $127 \pm 63$ & $123 \pm 62$ & 300 \\
\hline O071 & 49 & $201 \pm 105$ & $174 \pm 96$ & $162 \pm 90$ & $157 \pm 85$ & $154 \pm 82$ & 285 \\
\hline O093 & 54 & $217 \pm 107$ & $194 \pm 96$ & $185 \pm 94$ & $182 \pm 91$ & $181 \pm 88$ & 442 \\
\hline O094 & 51 & $251 \pm 132$ & $230 \pm 120$ & $224 \pm 116$ & $221 \pm 116$ & $222 \pm 117$ & 365 \\
\hline O150 & 35 & $176 \pm 86$ & $162 \pm 86$ & $155 \pm 87$ & $150 \pm 89$ & $148 \pm 89$ & 427 \\
\hline O205 & 66 & $143 \pm 131$ & $149 \pm 119$ & $148 \pm 112$ & $150 \pm 109$ & $154 \pm 107$ & 709 \\
\hline O293 & 67 & $175 \pm 106$ & $159 \pm 101$ & $156 \pm 101$ & $158 \pm 100$ & $162 \pm 99$ & 754 \\
\hline O296 & 56 & $198 \pm 139$ & $184 \pm 138$ & $181 \pm 132$ & $182 \pm 128$ & $186 \pm 125$ & 986 \\
\hline O474 & 68 & $145 \pm 84$ & $126 \pm 72$ & $119 \pm 65$ & $117 \pm 59$ & $115 \pm 54$ & 345 \\
\hline O626 & 53 & $233 \pm 125$ & $211 \pm 113$ & $200 \pm 110$ & $193 \pm 108$ & $189 \pm 107$ & 355 \\
\hline W675 & 90 & $174 \pm 106$ & $157 \pm 95$ & $154 \pm 87$ & $157 \pm 87$ & $159 \pm 87$ & 629 \\
\hline W685 & 43 & $187 \pm 91$ & $168 \pm 77$ & $170 \pm 87$ & $169 \pm 85$ & $169 \pm 85$ & 277 \\
\hline All & 684 & $186 \pm 114$ & $169 \pm 104$ & $164 \pm 100$ & $162 \pm 98$ & $162 \pm 97$ & 426 \\
\hline
\end{tabular}

levels of accuracy are in the mid-range compared with previous studies, which in particular for free-ranging animals appear heavily dependent on the degree of post-processing (Table 4). Part of the variation originates from extrinsic and intrinsic factors including time of year and location (affecting latitude estimation in particular), weather conditions, and although unimportant in our short-term study, uncorrected clock-drift over long deployments (see Wilson et al. in press for a recent review). Of these, weather effects are probably the most important, almost certainly accounting for the consistency in errors among days apparent for both static devices and free-ranging birds in our study. There are also differences in logger design; some incorporate a blue filter to ensure the photoreceptor records the light least sensitive to cloud cover, improving performance at least in static trials (Wilson et al. in press). Recording resolution also varies, although because the software incorporates algorithms that interpolate between records to determine the time that designated dawn/dusk light thresholds were reached, intervals of up to $15 \mathrm{~min}$ are adequate for geolocation (Hill 1994, Le Boeuf et al. 2000), and compared with other factors, the influence of recording interval on relative accuracy appears to be slight (Wilson et al. in press).

Table 3. Summary of position estimates for static GLS loggers at Bird Island, South Georgia

\begin{tabular}{|lcccc|}
\hline $\begin{array}{l}\text { Logger } \\
\text { ID }\end{array}$ & $\begin{array}{c}\text { No. of valid } \\
\text { locations }\end{array}$ & $\begin{array}{c}\text { Mean great-circle } \\
\text { error } \pm \text { SD }(\mathrm{km})\end{array}$ & $\begin{array}{c}\text { SD of latitudinal } \\
\text { error }\left({ }^{\circ}\right)\end{array}$ & $\begin{array}{c}\text { SD of longitudinal } \\
\text { error }\left({ }^{\circ}\right)\end{array}$ \\
\hline LM11 & 148 & $85.7 \pm 46.8$ & 0.62 & 1.01 \\
LM28 & 148 & $83.5 \pm 46.8$ & 0.60 & 0.97 \\
LM59 & 148 & $85.0 \pm 48.7$ & 0.62 & 1.00 \\
All & 444 & $84.7 \pm 47.3$ & 0.61 & 0.99 \\
\hline
\end{tabular}

In studies of flying birds, GLS loggers are usually leg-mounted, with the sensor of variable orientation, and potentially shaded, obscured by feathers if the leg is tucked into plumage during flight, or with light levels attenuated by water if the bird sits on the sea around dawn and dusk. These intermittent events account for the varying degrees of interference detected in light curves from bird-mounted (but not static) loggers in our study, and given their unpredictability are probably impossible to correct even with some form of curve replacement (cf. Wilson et al. 1995, in press for diving species). For highly mobile animals, there is the additional difficulty of producing in effect an instantaneous estimate of location at local midday and midnight using GLS (or control PTT fixes), which in the case of an albatross might have travelled $400 \mathrm{~km}$ in $12 \mathrm{~h}$. Although the relative time spent travelling during the day versus night can be incorporated in the algorithms, this assumes directed linear flight. This is an unlikely scenario for albatrosses foraging in a highly patchy and unpredictable marine environment, in which flight velocity and direction probably change continuously depending on encounter rate and profitability of prey patches.

Post-processing of data also affects both the real and the perceived accuracy of geolocation. Identification and subsequent removal of locations associated with obvious light level interference was critical in our study, and given the association with more or less random events (see above), the only drawback was a reduction in sample size (by $12 \%$ ). Other approaches to processing, however, might produce systematic biases. For example, removal of spurious locations requiring 

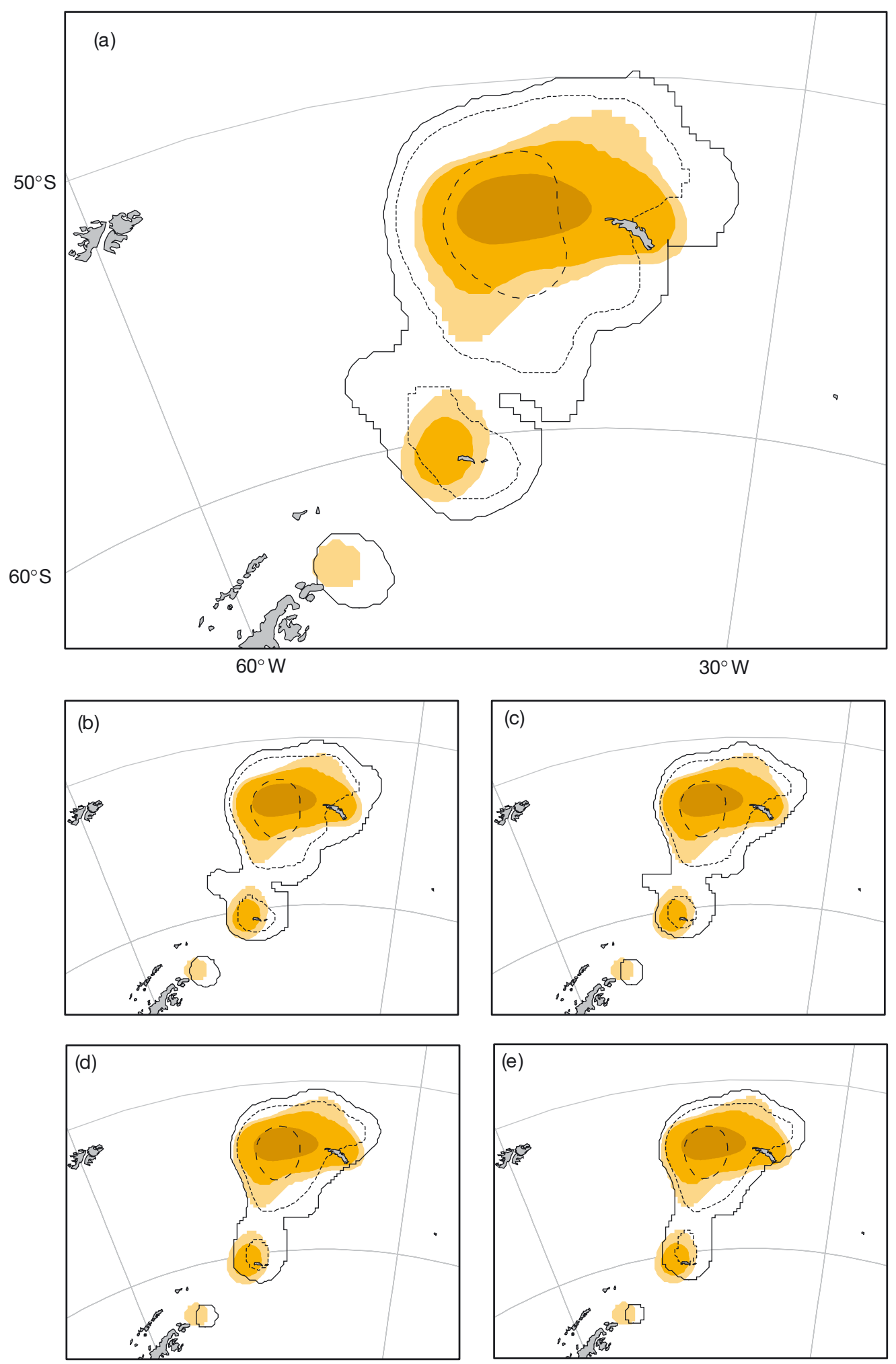

Fig. 2. Thalassarche melanophrys. Kernel density contours for GLS locations that were (a) unsmoothed, (b) smoothed $2 \times$, (c) smoothed $4 \times$, (d) smoothed $6 \times$, and (e) smoothed $8 \times$, overlaid on kernels from the mean PTT locations of 12 black-browed albatrosses tracked from South Georgia during chick-rearing in 2002. For GLS data, 95, 90 and $50 \%$ contours represented by solid, short dashed and long dashed lines, respectively. For PTT data, 95, 90 and 50\% contours represented by increasing darkness of colour tone 
Table 4. Review of geolocation errors in published studies. SST: sea surface temperature

\begin{tabular}{|c|c|c|c|}
\hline Deployment & Mean error $(\mathrm{km})$ & Details & Source \\
\hline \multicolumn{4}{|l|}{ Static trials } \\
\hline Stationary subsurface mooring & 137 & $\mathrm{n}=137$ locations, 4 accurate devices & Welch \& Eveson (1999) \\
\hline On land & $120-130$ & $\mathrm{n}=146 \mathrm{~d}$ & Wilson et al. (1992) \\
\hline On land & 110 & $\mathrm{n}=11$ locations from 5 devices & Beck et al. (2002) \\
\hline On land & $37.5,18.8^{\mathrm{a}}$ & $\mathrm{n}=14 \mathrm{~d}$ & Wilson et al. (in press) \\
\hline On land & 34 & $\mathrm{n}=52$ locations & Wilson et al. (1995) \\
\hline \multicolumn{4}{|l|}{ Free-ranging animals } \\
\hline $\begin{array}{l}\text { Elephant seals } \\
\text { Mirounga angustirostris }\end{array}$ & 148 & $\begin{array}{l}\text { Latitudinal ambiguities corrected by } \\
\text { matching logged SST with remote SST data }\end{array}$ & Le Boeuf et al. (2000) \\
\hline $\begin{array}{l}\text { Grey seals } \\
\text { Halichoerus grypus }\end{array}$ & $1043,94^{\mathrm{b}}$ & & Beck et al. (2002) \\
\hline $\begin{array}{l}\text { King penguins } \\
\text { Aptenodytes patagonicus }\end{array}$ & $352,102^{\mathrm{c}}, 70^{\mathrm{d}}$ & $\mathrm{n}=16$ locations from 1 individual & Wilson et al. (in press) \\
\hline $\begin{array}{l}\text { Magellanic penguins } \\
\text { Spheniscus magellanicus }\end{array}$ & $\begin{array}{l}\text { Within } 40-150 \\
\text { (no mean provided) }\end{array}$ & Depending on quality of light records & Wilson et al. (1995) \\
\hline $\begin{array}{l}\text { Rockhopper and Royal penguins } \\
\text { Eudyptes chrysocome } \\
\text { and E. schlegelis }\end{array}$ & $\begin{array}{c}383 \text { (latitude) } \\
189 \text { (longitude) }\end{array}$ & & Hull (1999) \\
\hline $\begin{array}{l}\text { Wandering albatrosses } \\
\text { Diomedea exulans }\end{array}$ & $\begin{array}{l}\text { As high as } 200 \\
\text { (no mean provided) }\end{array}$ & & Wilson et al. (2002) \\
\hline
\end{tabular}

unrealistic travel speeds is common practise in both GLS and PTT studies (e.g. Prince et al. 1998, Hull 1999), and has been incorporated into more complex algorithms (Beck et al. 2002). In this last study (see Table 4), corrected locations were available for only $60 \%$ of the original dataset, based to a large extent (58\% of cases) on the assumption that movements of $>148 \mathrm{~km}$ from the previous approved point were implausible. Although a degree of filtering is probably appropriate for most, if not all, studies, this should be approached cautiously as over-conservatism undoubtedly reduces the likelihood of detecting short-term, long-distance, exploratory excursions.

Smoothing, which reduces the variability in latitude and longitude estimates, is very effective in reducing the mean error in position estimates (Wilson et al. in press, this study). This approach works best if errors are random and independent (Welch \& Eveson 1999), which is not exactly true for GLS locations, as errors inevitably show some serial correlation because consecutive positions are derived from the same dawn and dusk events. Nonetheless, modelling of foraging ranges of black-browed albatrosses from smoothed datasets offered some advantages over unsmoothed locations, as errors in geolocation inevitably result in range inflation (Fig. 2). An unfortunate disadvantage of repeated smoothing, however, was the gradual contraction of the extremes of the range towards its centre, reducing the overlap with radial cores apparent in the control data. This was particularly obvious for indi- viduals that travelled furthest from the colony often to several cores (Table 2 and authors' unpubl. data). In a recent study, GLS data collected near the equinox from king penguins Aptenodytes patagonicus had to be smoothed 7 times to gain a realistic picture of foraging patterns (Pütz 2002). Although this seems reasonable given the simple range structure at that particular colony, our study indicates that over-smoothing can sometimes be misleading and should be applied cautiously for multinuclear GLS fix distributions.

In conclusion, this validation study illustrates the scale at which GLS devices are useful for tracking the movements of flying birds. Clearly with mean errors post-processing of 169 to $186 \mathrm{~km}$, GLS loggers have excellent potential for identifying foraging ranges of highly pelagic species during the breeding season, as well as tracking large-scale migration. Although range kernels estimated using GLS loggers are somewhat inflated, they nonetheless allow the clear demarcation of core feeding areas. The loggers used on blackbrowed albatrosses represented a compromise in terms of cost, battery longevity, memory capacity, recording resolution and sensor type (limited to a photoreceptor and a salt-water switch). Incorporation of a temperature probe to improve latitude estimation during the equinox (Delong et al. 1992), new approaches to data-processing (such as thresholdfree methods using the shape of light curves; www. lotek.com/library.htm\#adv), and further miniaturization are likely to increase the accuracy, as well as the 
number of potential target species. For migratory species in particular, the data generated will provide the first comprehensive opportunities to examine withinand between-season variation in foraging site-fidelity, and determine the mesoscale environmental characteristics associated with apparent winter hotspots. In addition, they will allow the unambiguous identification of areas of interaction and potential conflict with commercial fisheries. This is essential for effective conservation management, particularly for those species in which fisheries-associated mortality has resulted in recent catastrophic population declines (Weimerskirch et al. 1997, 1999, Croxall et al. 1998).

Acknowledgements. We are grateful to all the fieldworkers, and D. Roberts in particular, for help with instrument deployment and retrieval at Bird Island, and to Phil Ekstrom (Lotek) for keeping us informed of new developments in GLS data collection and processing techniques.

\section{LITERATURE CITED}

Afanasyev V (in press) A miniature daylight level and activity data recorder for tracking animals over long periods. Mem Nat Inst Polar Res (Jpn), Spec Issue 58

Beck CA, McMillan JI, Bowen WD (2002) An algorithm to improve geolocation positions using sea surface temperature and diving depth. Mar Mamm Sci 18:940-951

Block BA, Dewar H, Blackwell SB, Williams T and 5 others (2001) Migratory movements, depth preferences and thermal biology of Atlantic bluefin tuna. Science 293:1310-1314

Croxall JP, Prince PA, Rothery P, Wood AG (1998) Population changes in albatrosses at South Georgia. In: Robertson G, Gales R (eds) Albatross biology and conservation. Surrey Beatty \& Sons, Chipping Norton, p 69-83

Culik BM, Bannasch R, Wilson RP (1994) External devices on penguins: how important is shape? Mar Biol 118:353-357

DeLong RL, Stewart BS, Hill RD (1992) Documenting migrations of northern elephant seals using day length. Mar Mamm Sci 8:155-159

De Solla SR, Bonduriansky R, Brooks RJ (1999) Eliminating autocorrelation reduces biological relevance of home range estimates. J Anim Ecol 68:221-234

Grémillet D, Wilson RP, Wanless S, Chater T (2000) Blackbrowed albatrosses, international fisheries and the Patagonian Shelf. Mar Ecol Prog Ser 195:269-280

Hill RD (1994) Theory of geolocation by light levels. In: Le Boeuf BJ, Laws RM (eds) Elephant seals: population ecology, behaviour and physiology. University of California Press, Berkeley, CA, p 227-236

Hull CL (1999) The foraging zones of breeding royal (Eudyptes schlegeli) and rockhopper (E. chrysocome) penguins: an assessment of techniques and species comparison. Wildl Res 26:789-803

Le Boeuf BJ, Crocker DE, Costa DP, Blackwell SB, Webb PM, Houser DS (2000) Foraging ecology of northern elephant seals. Ecol Monogr 70:353-382

McConnell BJ, Chambers C, Fedak MA (1992) Foraging ecology of southern elephant seals in relation to bathymetry

Editorial responsibility: Otto Kinne (Editor),

Oldendorf/Luhe, Germany and productivity of the Southern Ocean. Antarct Sci 4: 393-398

Nel DC, Nel JL, Ryan PG, Klages NTW, Wilson RP, Robertson G (2000) Foraging ecology of grey-headed mollymawks at Marion Island, southern Indian Ocean, in relation to longline fishing activity. Biol Conserv 96:219-231

Nel DC, Ryan PG, Nel JL, Klages NTW, Wilson RP, Robertson G (2002) Foraging interactions between wandering albatrosses Diomedea exulans breeding on Marion Island and long-line fisheries in the southern Indian Ocean. Ibis 144(on-line):E141-E154

Phillips RA, Xavier JC, Croxall JP (2003) Effects of satellite transmitters on albatrosses and petrels. Auk 120:1082-1090

Prince PA, Croxall JP, Trathan PN, Wood AG (1998) The pelagic distribution of South Georgia albatrosses and their relationships with fisheries. In: Robertson G, Gales R (eds) Albatross biology and conservation. Surrey Beatty \& Sons, Chipping Norton, p 137-167

Pütz K (2002) Spatial and temporal variability in the foraging areas of breeding king penguins. Condor 104:528-538

Tuck GN, Polacheck T, Croxall JP, Weimerskirch H, Prince PA, Wotherspoon S (1999) The potential of archival tags to provide long-term movement and behaviour data for seabirds: first results from wandering albatrosses Diomedea exulans of South Georgia and the Crozet Islands. Emu 99: 60-68

Weimerskirch H, Wilson RP (2000) Oceanic respite for wandering albatrosses. Nature 406:955-956

Weimerskirch H, Brothers N, Jouventin P (1997) Population dynamics of wandering albatross Diomedea exulans and Amsterdam albatross D. amsterdamensis in the Indian Ocean and their relationships with long-line fisheries: conservation implications. Biol Conserv 79:257-270

Weimerskirch H, Catard A, Prince PA, Cherel Y, Croxall JP (1999) Foraging white-chinned petrels Procellaria aequinoctialis at risk: from the tropics to Antarctica. Biol Conserv 87:273-275

Welch DW, Eveson JP (1999) An assessment of light-based geoposition estimates from archival tags. Can J Fish Aquat Sci 56:1317-1327

Wilson RP, Grant WS, Duffy DC (1986) Recording devices on free-ranging marine animals: does measurement affect foraging performance. Ecology 67:1091-1093

Wilson RP, Ducamp JJ, Rees G, Culik BM, Niekamp K (1992) Estimation of location: global coverage using light intensity. In: Priede IM, Swift SM (eds) Wildlife telemetry: remote monitoring and tracking of animals. Ellis Horward, Chichester, p 131-134

Wilson RP, Scolaro JA, Peters G, Laurenti S, Kierspel M, Gallelli H, Upton J (1995) Foraging areas of Magellanic penguins Spheniscus magellanicus breeding at San Lorenzo, Argentina, during the incubation period. Mar Ecol Prog Ser 129:1-6

Wilson RP, Grémillet D, Syder J, Kierspel MAM and 7 others (2002) Remote-sensing systems and seabirds: their use, abuse and potential for measuring marine environmental variables. Mar Ecol Prog Ser 228:241-261

Wilson RP, Rees G, Lage J, Pütz K and 5 others (in press) Determination of animal position at sea using changes in diel light intensity. Proc 5th Eur Conf Wildlife Telemetry. CNRS, Strasbourg

Worton BJ (1995) Using Monte Carlo-simulation to evaluate kernel-based home range estimators. J Wildl Manag 59: $794-800$

Submitted: July 3, 2003; Accepted: August 30, 2003

Proofs received from author(s): January 20, 2004 